Check for updates

Cite this: RSC Adv., 2018, 8, 18576

\title{
Recent metal-catalysed approaches for the synthesis of cyclopenta[b]indoles
}

\author{
Thavaraj Vivekanand, Bishnupada Satpathi, Siddheshwar K. Bankar \\ and S. S. V. Ramasastry (D) *
}

Received 23rd April 2018

Accepted 14th May 2018

DOI: $10.1039 / \mathrm{c} 8 \mathrm{ra03480j}$

rsc.li/rsc-advances

\begin{abstract}
The cyclopenta[b]indole scaffold is ubiquitously present in several bioactive natural products and pharmaceutically interesting compounds. Of the numerous methods known for the synthesis of cyclopenta-fused indoles, this review highlights only the metal-catalysed approaches reported from the year 2015 onwards. This review encompasses our own efforts leading to the synthesis of cyclopentannulated indoles, in addition to the seminal contributions of several other researchers.
\end{abstract}

\section{Introduction}

The majority of natural products, synthetic drugs, agrochemicals and other biologically significant molecules are heterocyclic compounds, predominantly nitrogen-containing heterocycles. ${ }^{1}$ Consequently, synthesis of N-heterocycles became one of the main branches of synthetic chemistry. ${ }^{2}$ Among N-heterocycles, indole and indoline scaffolds are privileged substructures owing to their occurrence in a large number of natural products, bioactive compounds and materials of industrial relevance. ${ }^{3,4}$

Among indole derivatives, cyclopenta $[b]$ indoles are of great significance because of their prevalence in a large number of alkaloids possessing wide-ranging biological activities. ${ }^{5}$ For example, fischerindole L shows cytotoxicity against $\mathrm{HCl}-\mathrm{H} 460$ cell lines, ${ }^{6}$ terpendole $\mathrm{E}$ is an important mitotic kinesin Eg5 inhibitor, ${ }^{7}$ yuehchukene possesses anti-fertility and estrogenic activities, ${ }^{\mathbf{8}}$ bruceollines are traditionally used for treating malaria and other parasitic diseases, ${ }^{9}$ paspaline exhibits antibacterial and insecticidal activity, ${ }^{\mathbf{1 0}}$ and drugs such as laropiprant, which is believed to have a cholesterol lowering effect, ${ }^{11}$ possess a cyclopenta $[b]$ indole core, while polyveoline ${ }^{12}$ represents an example of natural products having a cyclopenta $[b]$ indoline scaffold (Fig. 1).

Due to their significant biological properties, various synthetic protocols have therefore been described to prepare cyclopenta $[b]$ indoles. Some of the prominent approaches include, $[3+2]$-cycloaddition, ${ }^{\mathbf{1 3}}$ Yonemitsu condensation, ${ }^{\mathbf{1 4}}$ gold(I) catalysed Rautenstrauch rearrangement, ${ }^{15}$ bismuth(III) catalysed condensation, ${ }^{16}$ Nazarov cyclisation, ${ }^{17}$ Heck-Suzuki cascade, ${ }^{\mathbf{1 8}}$ Fischer indole synthesis, ${ }^{\mathbf{1 9}}$ indole electrophilic

Organic Synthesis and Catalysis Lab, Department of Chemical Sciences, Indian Institute of Science Education and Research (IISER) Mohali, Knowledge City, Sector 81, S. A. S. Nagar, Manauli PO, Punjab 140306, India ; Web: http://14.139.227.202/ faculty/sastry/.E-mail: ramsastry@iisermohali.ac.in; ramsastrys@gmail.com substitution reactions, ${ }^{\mathbf{2 0}}[3,3]$-sigmatropic rearrangement, ${ }^{21}$ Dieckmann condensation, ${ }^{22}$ vinylogous Michael addition/Friedel-Crafts reaction, ${ }^{23}$ enzymatic synthesis, ${ }^{24}$ etc.

In the past few decades, chemists have extensively explored various routes for the synthesis of cyclopenta[b]indoles via metal catalysis and these efforts have been reviewed recently. ${ }^{25}$ The scope of the present review is to provide a detailed account of various metal-catalysed approaches reported for cyclopenta $[b]$ indoles from the year 2015 onwards. The works highlighted herein have been categorised based on the metal catalyst employed.

\section{Palladium-catalysed approaches}

In 2017, Lu and Han reported a Pd(II)-catalysed tandem cyclisation of alkynones 1 to synthesise pentaleno[2,1- $b$ ]indoles 2 (Scheme 1). ${ }^{26}$ Tetracyclic indoles bearing two neighbouring stereogenic centres, one being all-carbon quaternary, were constructed in a single operation in an excellent diastereoselectivity. The tandem cyclisation is initiated by the transamino palladation of the alkyne moiety to generate 3 . A subsequent nucleophilic addition of the C-Pd bond to the intramolecular carbonyl group followed by the protonolysis of 4 results in the formation of product 2 . Thereby, this reaction offers an efficient and atom-economic alternative for the synthesis of pentaleno[2,1- $b]$ indoles 2 .

In 2018, Cheng and Zhai demonstrated a novel Pd-catalysed decarboxylative coupling reaction of vinyl benzoxazinanones 6 with aryne precursors 5 to achieve the synthesis of cis-tetrahydroindeno[2,1- $b]$ indoles 7 in good yields (Scheme 2). ${ }^{27}$ The authors propose that the mechanism involves a nucleophilic attack at the central carbon of vinyl benzoxazinanone-derived $\pi$ allyl palladium species $\mathbf{8}$ that gives a palladacyclobutane intermediate $\mathbf{9}$, which then reacts with arynes to afford the polycyclic heterocycles such as 7 . 

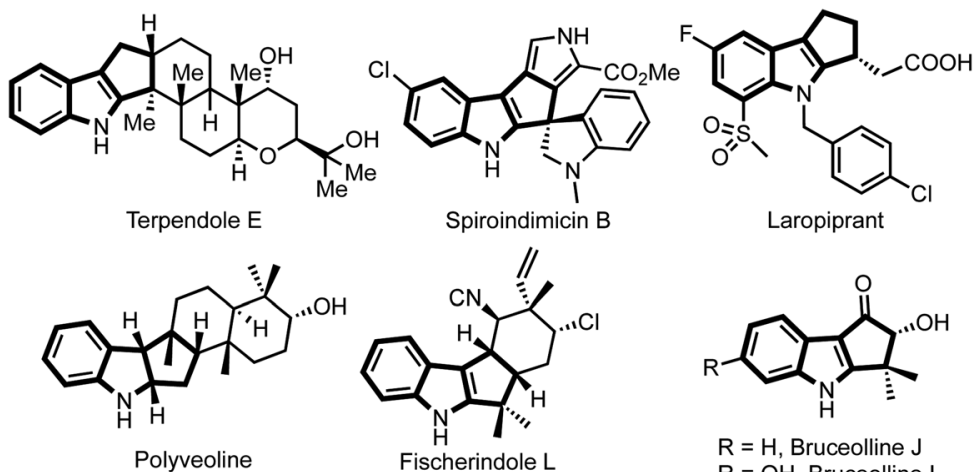

Laropiprant

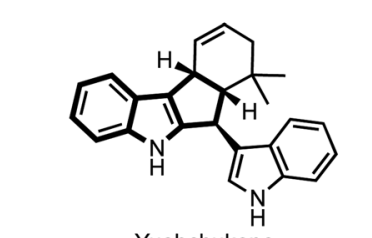

Fischerindole L

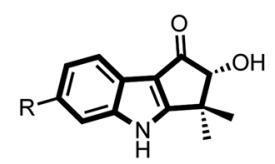

$R=H$, Bruceolline $J$

$\mathrm{R}=\mathrm{OH}$, Bruceolline I
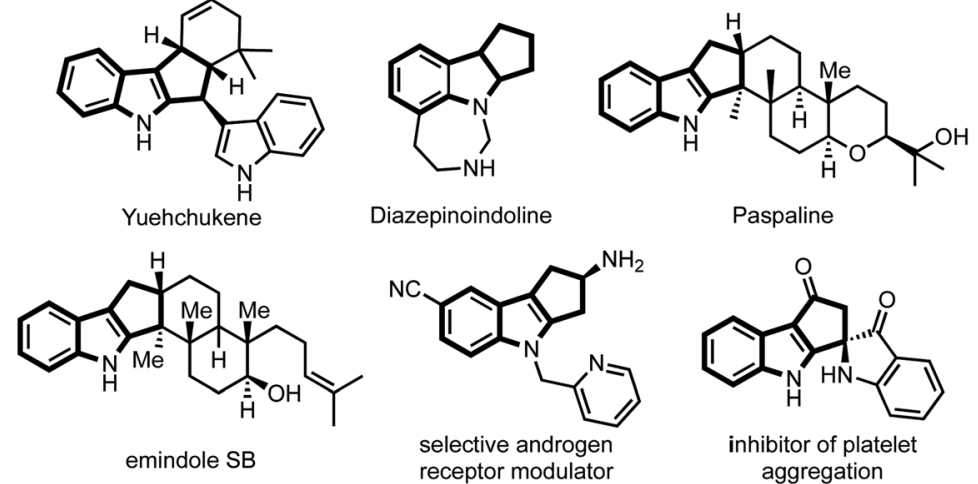

Paspaline

emindole SB receptor modulator

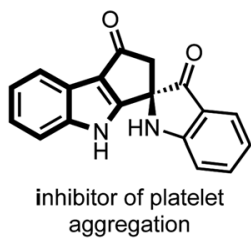

Fig. 1 Representative natural products and medicinally significant compounds possessing cyclopenta[b]indole core.

Kotha and Gunta reported an interesting approach for the synthesis of fused N-heterocycles (for example, 12 and 13) via $\mathrm{C}-\mathrm{H}$ activation and ring-rearrangement metathesis (RRM) of 2bromo- $N$-protected anilines 10 (or 11) with norbornadiene (Scheme 3). ${ }^{28}$ Through this method, various structurally intricate polycyclic amides were prepared, and some of the products obtained herein represent the core structures of the bioactive<smiles>[R1]NC1=C(C#CCC2([R])C(=O)CCC2=O)C=C[R1]C=C1</smiles>

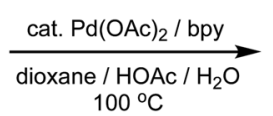
$100^{\circ} \mathrm{C}$

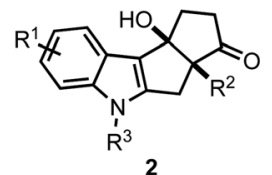

up to $98 \%$ yield $R^{3}=T s, M s$

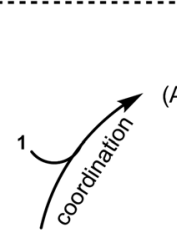<smiles>CC(=O)OCC1(C(C)=O)CCCC1=O</smiles>

$\mathrm{Pd}(\mathrm{OAc})_{2}$
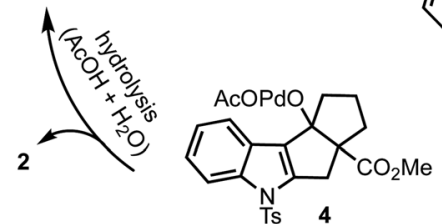
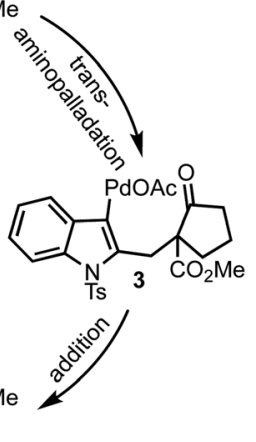

Scheme 1 Palladium-catalysed tandem cyclisation leading to the formation of pentaleno[2,1-b]indoles.
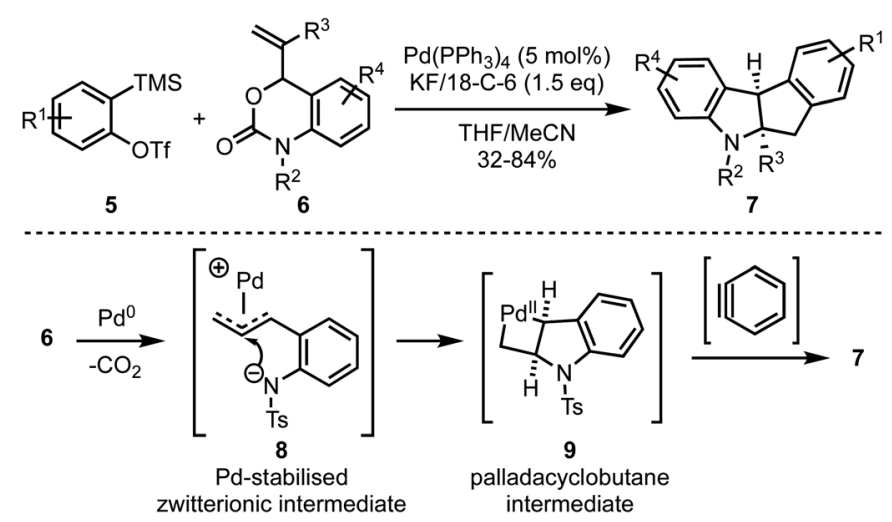

Scheme 2 A Pd-catalysed synthesis of tetrahydroindeno[2,1- $b$ ] indoles.
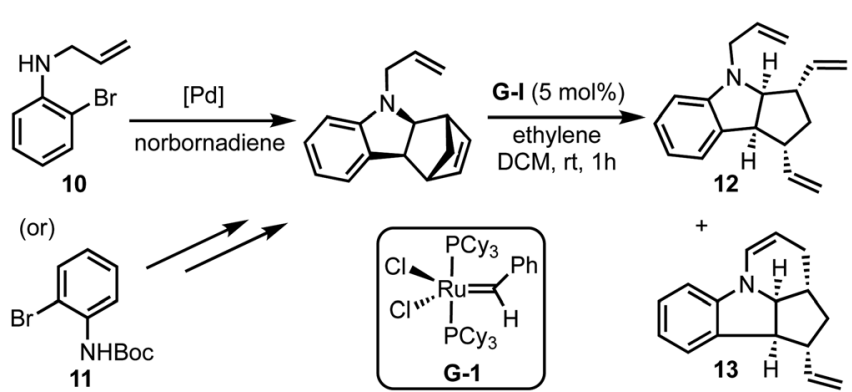

Scheme 3 Kotha's synthesis of fused-indolines via $\mathrm{C}-\mathrm{H}$ activation and ring-rearrangement metathesis. 


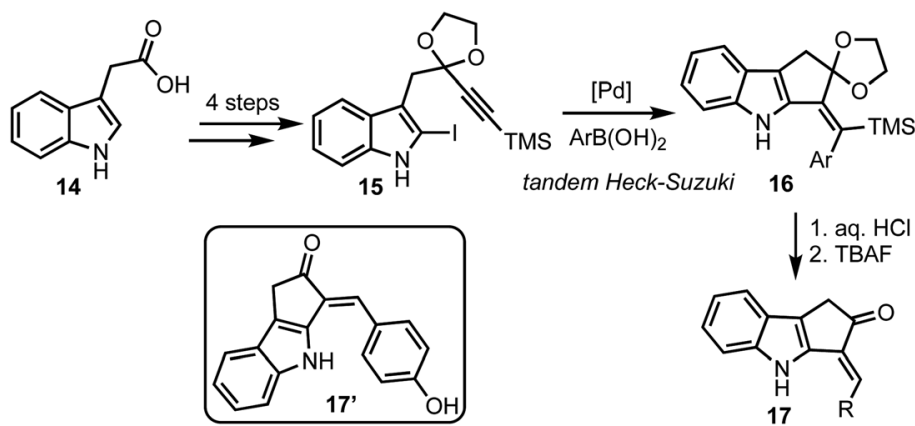

Scheme 4 Mårtensson's synthesis of bioactive cyclopenta[b]indoles.

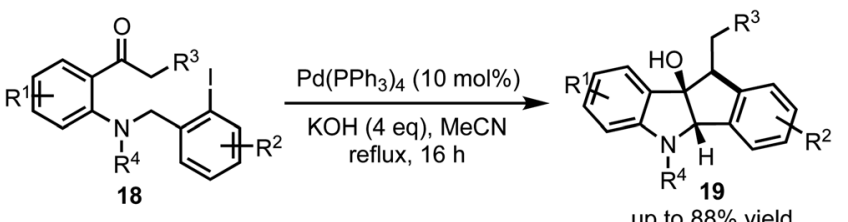

up to $88 \%$ yield

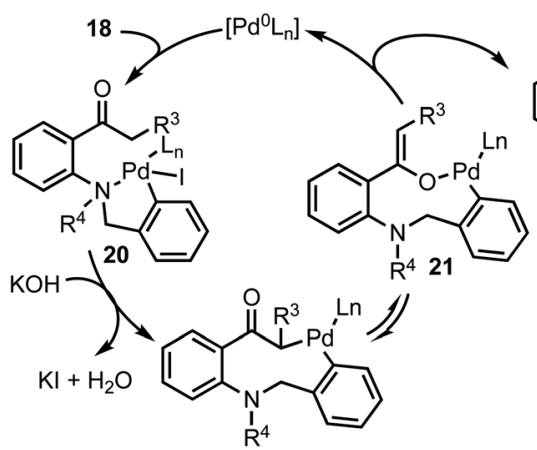

Scheme 5 Wang's approach for cyclopenta-fused indolines.

alkaloids epimeloscine, deoxycalyciphylline $\mathrm{B}$, daphlongamine $\mathrm{H}$ and isodaphlongamine $\mathrm{H}$. Key advantages of the $\mathrm{C}-\mathrm{H}$ activation/RRM strategy are: (i) it is atom-economical, and (ii) provides access to intricate molecular scaffolds amenable for further synthetic transformations.

In 2015, Mårtensson and co-workers developed a diversity oriented synthesis of 3-arylidine-cyclopenta[b]indol-2-ones $\mathbf{1 7}$

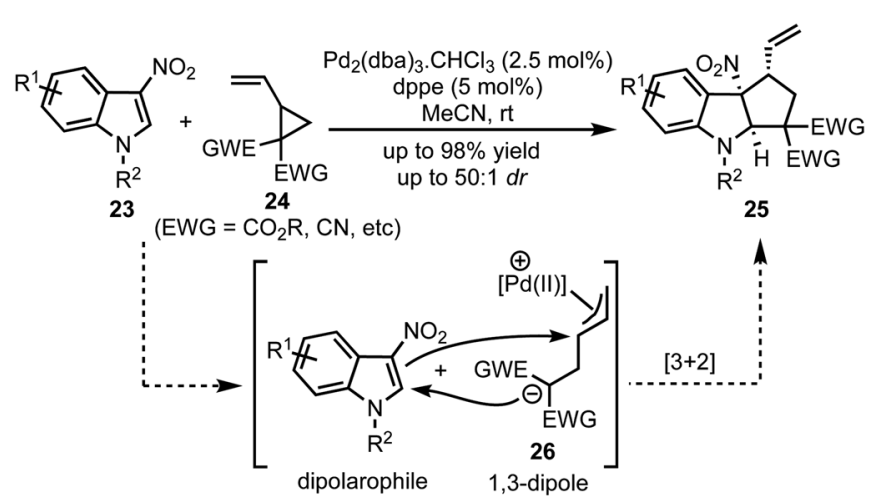

Scheme 6 Vitale's synthesis of fused cyclopentannulated indolines.
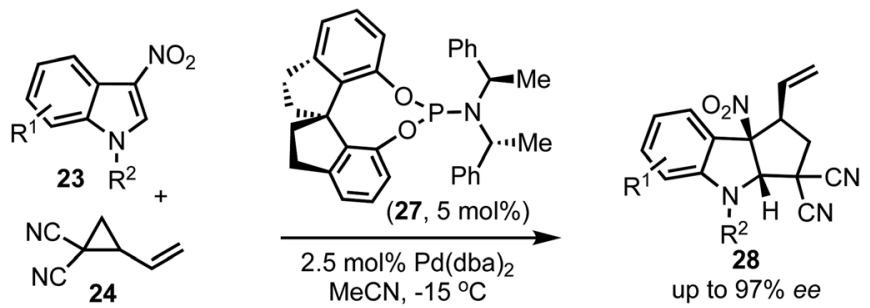

up to $97 \%$ ee

Scheme 7 Shi's catalytic synthesis of chiral cyclopenta-fused indolines.

via Pd-catalysed Heck-Suzuki reaction cascade (Scheme 4). ${ }^{29}$ Indole-3-acetic acids 14 were converted to iodoindoles 15 in four steps. A tandem Heck-Suzuki reaction of $\mathbf{1 5}$ provided access to cyclopenta-fused indoles 16, which were converted to enones 17 in two straight forward steps. Among several analogs of 17 prepared, $\mathbf{1 7}^{\prime}$ particularly displayed impressive anti-melanoma

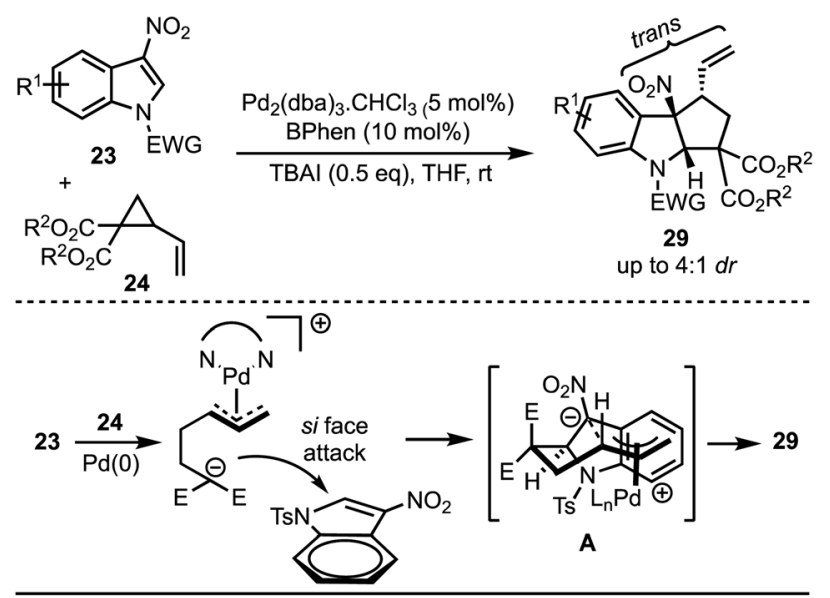

Vitale's work leading to cis-cyclopenta[b]indolines

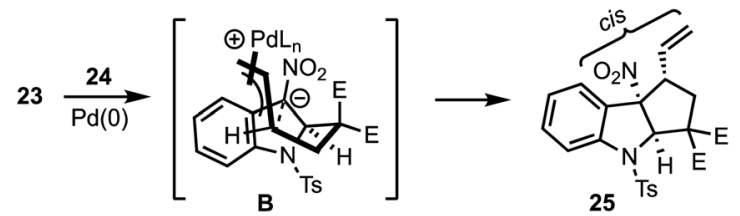

Scheme 8 Hyland's diastereoselelctive synthesis of cyclopenta[b] indolines. 
<smiles>[R1]n1cc([N+](=O)[O-])c2cc[R1]cc21</smiles>
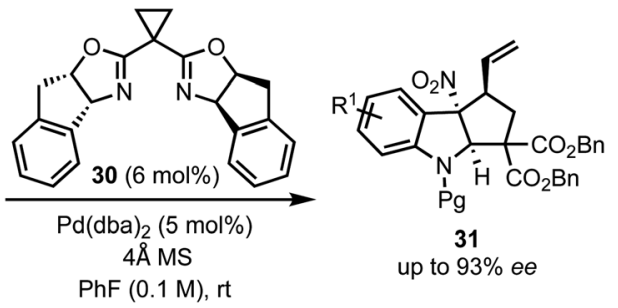

up to $93 \%$ ee

Scheme 9 Wang's synthesis of cyclopenta[b]indolines via Pd-catalysed asymmetric dearomative cycloaddition.

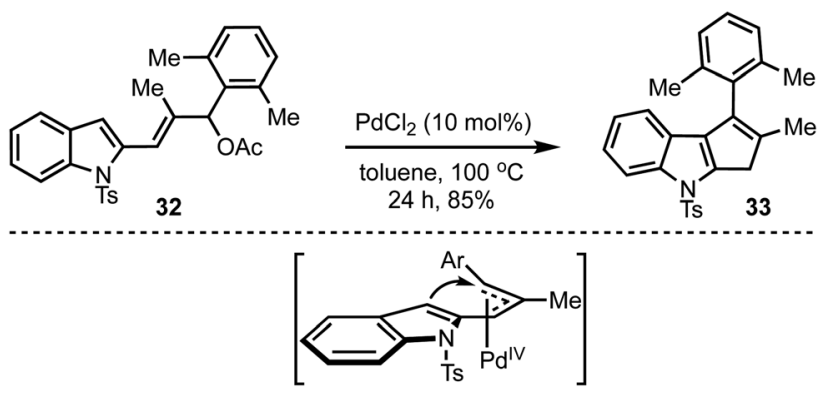

Scheme $10 \mathrm{Pd}$-catalysed iso-Nazarov-type cyclisation.

properties by inhibiting Aurora A, Aurora B, BRAF V600E, IRAK4 and also inhibiting cell proliferating PBMC. In addition, $\mathbf{1 7}^{\prime}$ also displayed interesting fluorescent properties, enabling its intracellular accumulation to be visualised.

Synthesis of dihydro[1,2-b]indenoindole-9-ols 19 through a Pd-catalysed cascade process was developed by Wang and coworkers (Scheme 5$)^{30}$ The mechanism involves an oxidative addition of $\operatorname{Pd}(0)$ with an aryl iodide 18 leading to the formation of a chelation stabilised intermediate 20. Subsequently, basemediated generation of nine-membered palladacycle 21 undergoes reductive elimination to form 8-membered $\beta$-arylated compound 22. Further base-mediated intramolecular cyclisation furnished 19 in good yields. The control experiments and the isolation of 8 -membered $\beta$-arylated intermediate 22 further ascertain the proposed palladium cycle.

In 2017, Vitale and co-workers disclosed a highly efficient and atom-economical $\operatorname{Pd}(0)$-catalysed dearomative $[3+2]$ -<smiles>[Y4][Y4]1c2c(c(C([R])=C)c1C=O)C=[W]=[C+]2</smiles>

$\mathrm{X}=\mathrm{NR} \mathrm{R}^{3}, \mathrm{O}, \mathrm{S}$

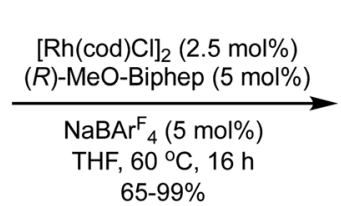
$65-99 \%$

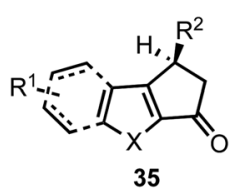

up to $99 \%$ ee
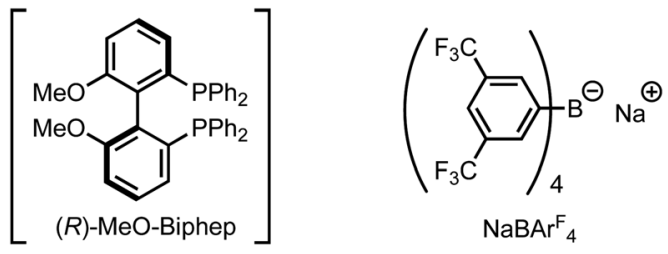

Scheme 11 Rh-catalysed intramolecular hydroacylation for the synthesis of dihydrocyclopenta[b]indol-1(2H)-ones.

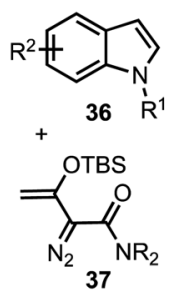

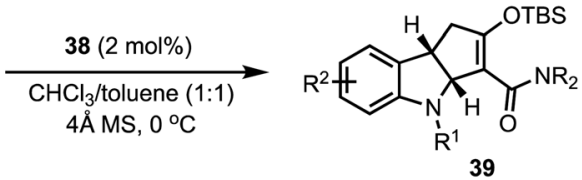

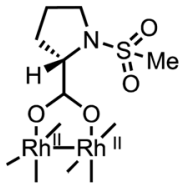<smiles>[R16]C([Y16])C1CC1C(=O)O</smiles>

38, $\mathrm{Rh}_{2}(\mathrm{~S}-\mathrm{MSP})_{4}$

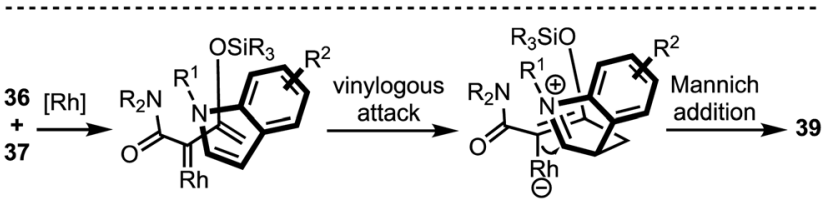

Scheme 12 Rh-catalysed approach for cyclopenta-fused indolines.

cycloaddition of 3-nitroindoles 23 with vinylcyclopropanes $\mathbf{2 4}$ to obtain cyclopentannulated indolines 25 possessing three stereogenic centers in high diastereoselectivity (Scheme 6). ${ }^{31}$ The zwitterionic 1,3-dipole 26 undergoes Michael addition with the electrophilic 3-nitroindoles. This follows an irreversible intramolecular attack of the nitronate anion onto the $\pi$-allyl palladium(II) moiety to afford 2,3-fused cyclopenta[ $b]$ indolines 25 in a stereo-defined fashion.

In 2018, Shi and co-workers demonstrated the catalytic asymmetric dearomative $[3+2]$-cycloaddition of electron-
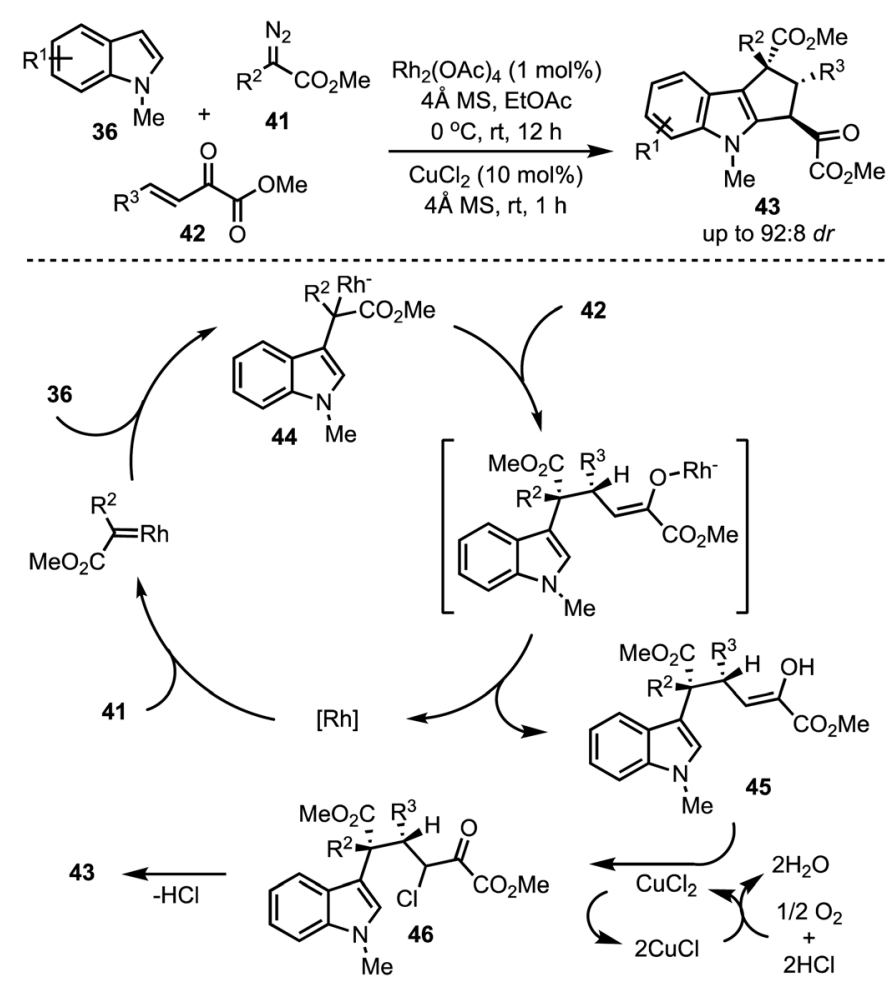

Scheme 13 Hu's one-pot sequential dehydrogenative coupling reaction. 


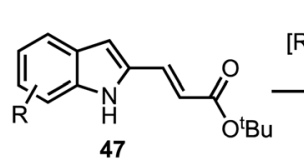

$\mathrm{ArB}(\mathrm{OH})_{2}(2 \mathrm{eq})$ $\left[\mathrm{Rh}(\mathrm{coe})_{2} \mathrm{Cl}\right]_{2}(2.5 \mathrm{~mol} \%)$

$48(5 \mathrm{~mol} \%)$

$\mathrm{K}_{3} \mathrm{PO}_{4}(1.5 \mathrm{M}, 3 \mathrm{eq})$ dioxane, $60^{\circ} \mathrm{C}$

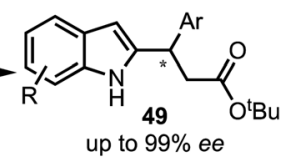
up to $99 \%$ ee \begin{tabular}{l|l} 
1. $\mathrm{BnCl}, \mathrm{KOH}$ & 4. NIS \\
2. $\mathrm{LAH}$ & 5. ${ }^{n} \mathrm{BuLi}$ \\
3. $\mathrm{CBr}_{4}, \mathrm{PPh}_{3}$ &
\end{tabular}
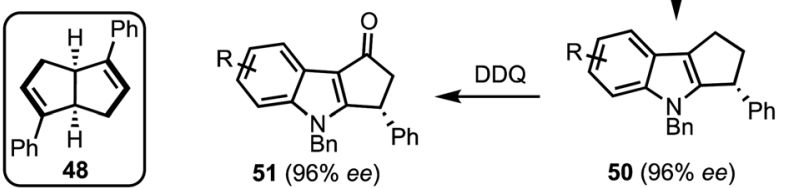

$50(96 \%$ ee $)$

Scheme 14 Xu's synthesis of cyclopenta[b]indoles.

deficient indoles with 1,3-dipoles (Scheme 7). ${ }^{32}$ For example, phosphoramidite 27 catalysed reaction of 3-nitroindoles 23 with vinyl cyclopropanes $\mathbf{2 4}$ provided chiral cyclopenta[b]indolines 28 in high enantioselectivities (up to 97\% ee). This also presents a case for catalytic asymmetric dearomatisation (CADA) reactions, which are well-known for electron-rich indoles, but in this case, the authors have demonstrated the CADA concept on electron-poor indoles to obtain chiral cyclopenta $[b]$ indolines of the type $\mathbf{2 8 .}$

In 2017, Hyland and co-workers reported a Pd-catalysed diastereoselective synthesis of cyclopenta $[b]$ indolines 29 from 3-nitro indoles 23 and vinylcyclopropane dicarboxylates 24 by Pd-catalysed dearomative [3 +2$]$-cycloaddition process (Scheme 8). ${ }^{33}$ The authors have identified that the halide addition [in the form of tetrabutylammonium iodide (TBAI)] is critical for the diastereo induction in products. It was hypothesised that the halide allows a Curtin-Hammett control of the reaction there by introducing diastereoselectivity. Unlike Vitale's work, ${ }^{31}$ a switch

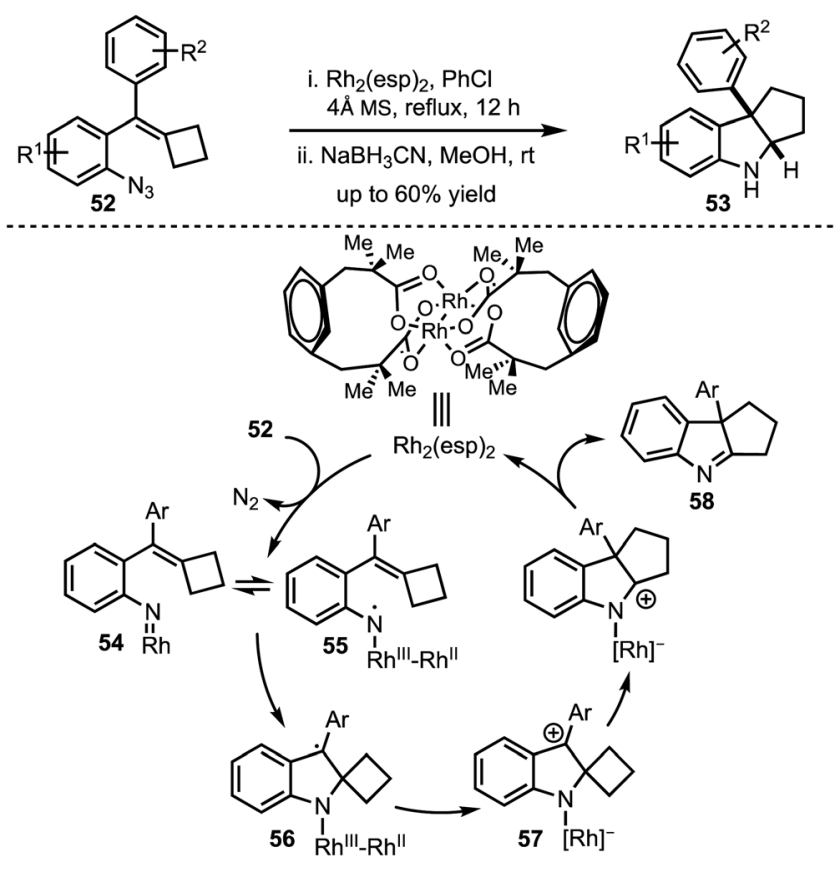

Scheme 15 Rh-catalysed synthesis of pentannulated indoles. in the diastereoselectivity was observed with the vinyl and nitro groups being trans to each other. The difference between the transition states involved in Hyland's work (A) and Vitale's work (B) is presented in Scheme 8.

In 2018, Wang's group reported a Pd-catalysed asymmetric dearomative $[3+2]$-cycloaddition strategy for the construction of optically active cyclopenta-fused indolines 31 (Scheme 9). ${ }^{34}$ For example, the reaction of 3-nitroindoles 23 with vinyl cyclopropanes 24 in the presence of a chiral box $(30) / \operatorname{Pd}(0)$ complex delivered $8 b$-nitro hexahydrocyclopenta $[b]$ indoles 31 containing up to three contiguous chiral centres in high yields and good regio-, chemo-, and enantioselectivities. The synthetic utility of this method was demonstrated through direct functionalisation of the carbon-carbon double bond of 31. The salient features of this transformation include good functional group tolerance, stereospecificity, atom-economy, and scalability.

Recently, our group demonstrated a Pd-catalysed TrostOppolzer type Alder-ene reaction of 2,4-pentadienyl acetates for the synthesis of cyclopentadienes and cyclopentene-fused arenes and heteroarenes. For example, in the presence of a catalytic amount of palladium chloride, the allyl acetate $\mathbf{3 2}$ afforded the cyclopenta $[b]$ indole 33 in good yield (Scheme 10). ${ }^{35}$ The reaction is believed to involve the formation of a $\pi$-allyl palladium complex and an intramolecular Alder-ene reaction as in the model depicted in Scheme 10. The overall reaction also represents an unprecedented acid-free iso-Nazarov-type cyclization.

\section{Rhodium-catalysed approaches}

In 2017, Vickerman and Stanley reported an enantioselective approach for the synthesis of N/O/S-heterocycles 35 by the intramolecular Rh-catalysed hydroacylation of olefins $\mathbf{3 4}$ (Scheme 11). ${ }^{36}$ Employing this strategy, 1,4-dihydrocyclopenta $[b]$ indol-3 $(2 H)$-ones and 3,4-dihydrocyclopenta $[b]$ indol-1 $(2 H)$ ones are accessible in high yields and in excellent enantioselectivities. This protocol allowed the alkene hydroacylation of 3vinylfuran-, 3-vinyl benzothiophene-, and 3-vinyl thiophene-2carboxaldehydes to generate the corresponding oxygen, and sulphur-containing heterocycles in chiral fashion.

Doyle and co-workers developed a highly regio-and enantiocontrolled formal [3+2]-annulation of indoles and electrophilic enol carbenes for the synthesis of chiral cyclopenta-fused indolines 39 (Scheme 12). ${ }^{37}$ An enantioselective vinylogous addition of enoldiazoacetamides 37 to $N$-substituted indoles 36 (without 2- or 3-substituents) was facilitated by the prolinateligated dirhodium(II) catalyst 38. Interestingly, the donoracceptor cyclopropane $\mathbf{4 0}$ was realised to be the carbene precursor in this transformation. It is interesting to note that prior to this study, dearomatising $[3+2]$-annulation of 2 - or 3 unsubstituted indoles that occurs with good chemo-, regio-, and enantiocontrol was not achieved.

In 2016, $\mathrm{Hu}$ and co-workers reported a Rh-catalysed highly diastereoselective three-component reaction for the generation of polyfunctionalised cyclopenta $[b]$ indoles 43 (Scheme 13). ${ }^{38}$ $\mathrm{Rh}_{2}(\mathrm{OAc})_{4}$ catalysed dehydrogenative coupling between indoles 36 and diazoacetates 41 generates intermediate 44. A subsequent trapping of $\mathbf{4 4}$ with $\alpha, \beta$-unsaturated- $\alpha$-keto esters $\mathbf{4 2}$ 


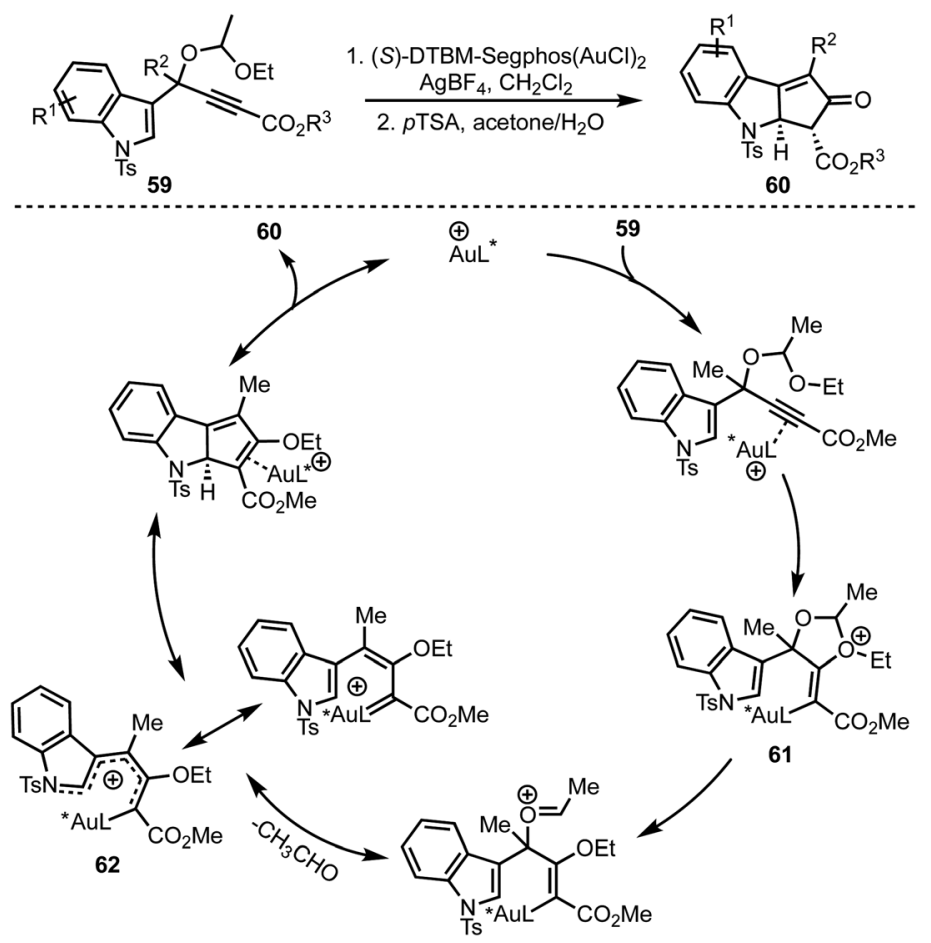

Scheme 16 Toste's Au-catalysed dearomative Rautenstrauch rearrangement for the synthesis of cyclopenta[b]indoles.

through Michael addition results in the formation of the enol 45. An aerobic intramolecular direct $\mathrm{Csp}^{2}-\mathrm{Csp}^{2}$ cross-coupling of indole-enol is promoted by $\mathrm{CuCl}_{2}$. Further, XPS and control experiments revealed the role of $\mathrm{Cu}(\mathrm{II})$ in the single electron transfer oxidation [a catalytic cycle of $\mathrm{Cu}(\mathrm{II})$ to $\mathrm{Cu}(\mathrm{I})$ ] of the enol 45 to $\alpha$-chloro carbonyl intermediate 46. An intramolecular Friedel-Crafts-type alkylation of $\mathbf{4 6}$ delivers the cyclopenta[$[b]$ indoles 43.

In 2017, $\mathrm{Xu}$ and co-workers developed a Rh-catalysed asymmetric $\beta$-arylation of indole-derived $\alpha, \beta$-unsaturated esters and aryl boronic acids for the synthesis of 3-(1H-indol-2-yl)-3arylpropanoates 49 in good yields and excellent enantioselectivities (Scheme 14).$^{39}$ The method is applicable to $\alpha, \beta$-unsaturated benzofuran- and benzothiophene-derived acrylates as well. The $\beta$ arylated products obtained herein were transformed to cyclopenta $[b]$ indoles 50 via a multistep sequence. A 2,3-dichloro-5,6dicyanobenzoquinone (DDQ)-mediated oxidation of $\mathbf{5 0}$ further provided functionalised cyclopenta-fused indoles of the type $\mathbf{5 1}$.

In 2016, Tang and Shi demonstrated a ring expansion of styrylazides 52 via $\mathrm{Rh}$ (II)-catalysed single electron transfer mechanism (Scheme 15).$^{40}$ The reaction path follows an initial Rh-nitrene $\mathbf{5 4}$ formation via nitrogen elimination and subsequent single electron transfer to generate the radical $\mathbf{5 5}$. The radical addition to the olefin generates the spirocyclic radical 56 which undergoes another SET to form 57. Further, 1,2-alkyl migration of $\mathbf{5 7}$ and elimination affords the imine 58. In situ borohydride reduction of the imine $\mathbf{5 8}$ delivers pentannulated indoles $\mathbf{5 3}$ in a highly diastreoselective manner. The authors also provided an evidence in favor of the generation of $\mathrm{Rh}^{\mathrm{III}}-\mathrm{Rh}^{\mathrm{II}}$-nitrene with DFT studies.

\section{Gold-catalysed approaches}

In 2015, Toste and co-workers reported a highly enantioselective dearomative Rautenstrauch rearrangement of propargyl acetals 59 catalysed by cationic (S)-DTBM-Segphos gold(I) (Scheme 16). ${ }^{15}$ This reaction provides a straightforward method for the preparation of enantioenriched cyclopenta[$[b]$ indoles $6 \mathbf{6 0}$.

The proposed mechanism involves an anti-attack of ethoxy ether of the acetal on to the Au-coordinated alkyne leading to the formation of oxonium species 61. An eventual extrusion of acetaldehyde generates gold-substituted 1-amino pentadienyl intermediate 62. An enantio-determining imino-Nazarov cyclisation of 62 followed by protodeauration affords product 60 .

Recently, our group reported the synthesis of 1,2,3-trisubstituted cyclopenta $[b]$ indoles 64 from 1-(2-aminophenyl)prop-2-ynols 63 via one-pot relay $\mathrm{Au}(\mathrm{I}) / \mathrm{Br} Ø$ nsted acid catalysis (Scheme 17) ${ }^{41}$

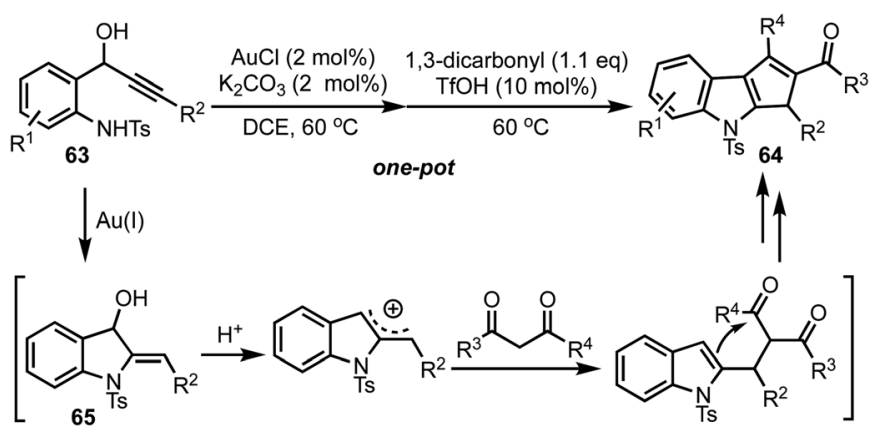

Scheme 17 A sequential Au(I)/BrØnsted acid catalysis. 

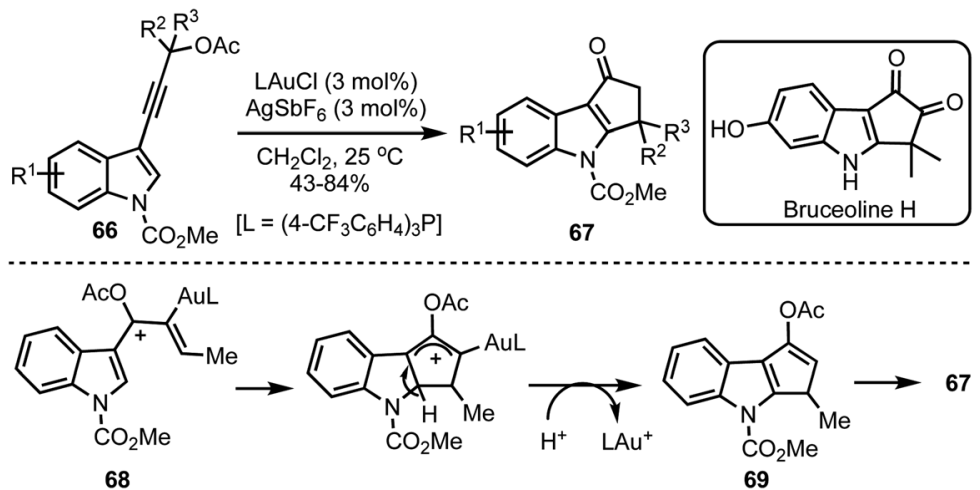

Scheme 18 Occhiato's tandem Au(I)-catalysed rearrangement/Nazarov cyclisation.

The reaction of ynols 63 under $\mathrm{Au}(\mathrm{I})$ catalysis generates indolines 65, which undergoes an acid mediated cation-ene reaction with 1,3-dicarbonyls and a subsequent intramolecular Friedel-Craftstype reaction to provide 64. It is noteworthy to mention that $\mathrm{Au}(\mathrm{I})$ or $\mathrm{Ag}(\mathrm{I})$ alone or a combination of $\mathrm{Au}(\mathrm{I})$ and silver based Lewis acids failed to deliver the indoline $\mathbf{6 5}$, whereas $\mathrm{Au}(\mathrm{I})$ with a combination of a base (such as $\mathrm{K}_{2} \mathrm{CO}_{3}$ ) was found to be effective. The reaction tolerates a wide range of ynols possessing electron donating as well as withdrawing groups. A variety of 1,3-dicarbonyls, 1,2,3-tricarbonyls, $\beta$-ketoesters and $\beta$-ketoamides are also tolerated under the reaction conditions.

Occhiato and co-workers developed a tandem gold(I)-catalysed rearrangement/Nazarov cyclisation of enynyl acetates 66 to obtain cyclopenta $[b]$ indol-1-ones 67 in good yields (Scheme 18). ${ }^{42}$ The process entails the gold(I)-catalysed [3,3]-sigmatropic rearrangement of the propargylic acetates 66 to generate requisite pentadienyl cation 68 . The Nazarov cyclisation

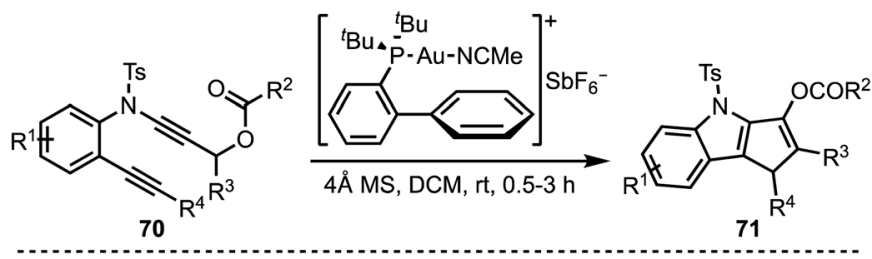

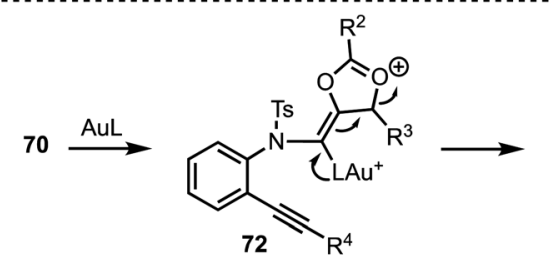
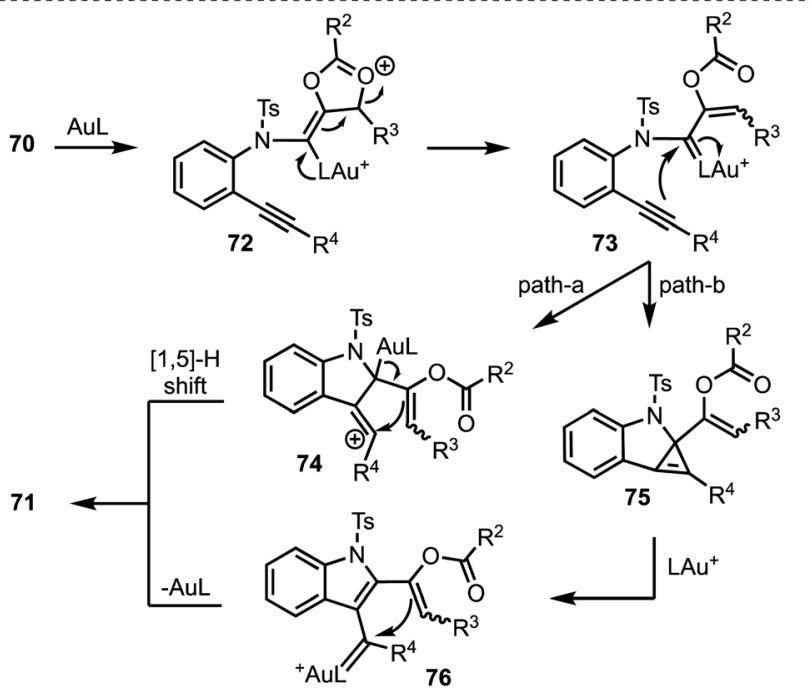

Scheme 19 Liu's synthesis of dihydrocyclopenta[b]indoles. followed by hydrolysis of the enol acetate 69 generates cyclopenta $[b]$ indol-1-ones 67 . The potential of this synthetic methodology was demonstrated in the total synthesis of Bruceolline $\mathrm{H}$.

Liu and co-workers presented a gold-catalysed cycloisomerisation of 1,6-diynes 70 containing a ynamide propargyl ester functionality, leading to the synthesis of densely functionalised 1,4-dihydro cyclopenta $[b]$ indoles 71 (Scheme 19). ${ }^{\mathbf{4 3}}$ The reaction proceeds through a selective activation of ynamide propargyl ester by $\mathrm{Au}(\mathrm{I})$ to afford $\alpha$-vinyl gold carbenoid $\mathbf{7 2}$. Intramolecular attack of the alkyne moiety on to the gold carbenoid (in 73) affords vinyl cationic species 74, which undergoes $[1,5]-H$ shift to furnish the product 71 (path a). On the other hand, transfer of the gold carbenoid moiety across the alkyne in $\mathbf{7 3}$ generates 76, via the cyclopropene intermediate $\mathbf{7 5}$. Intramolecular cyclisation of the enol acetate on to the gold

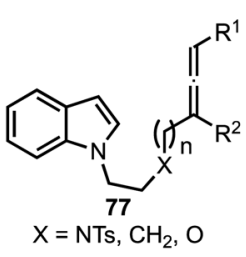
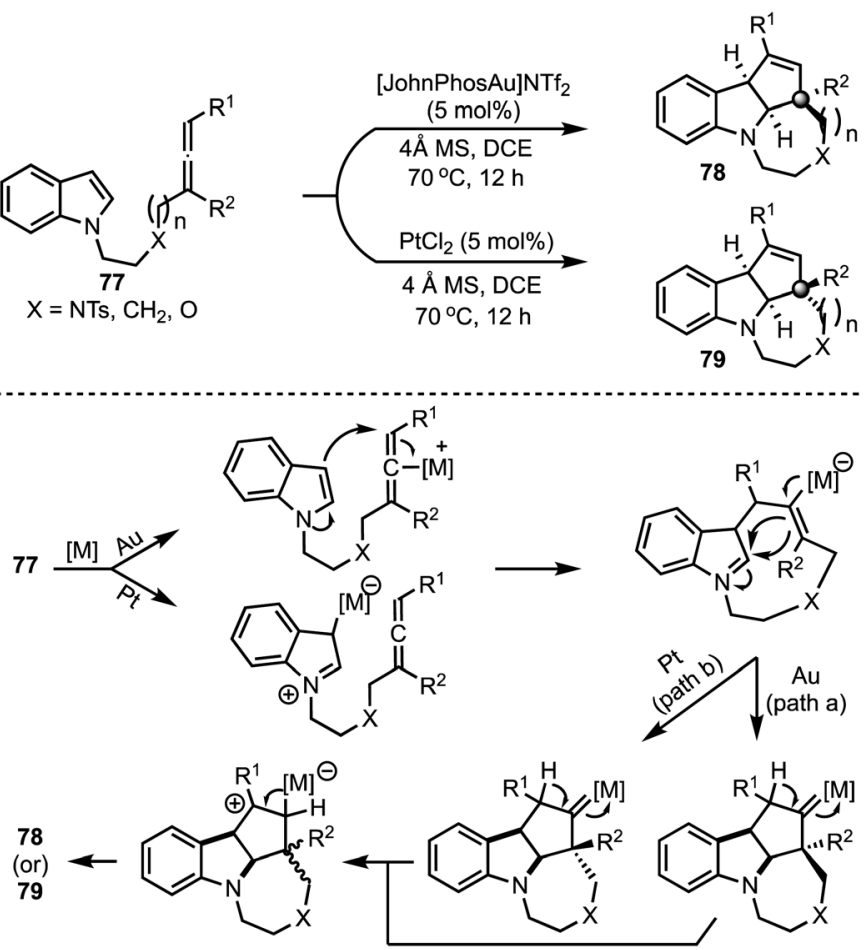

Scheme 20 Shi's Au- and Pt-catalysed cycloaddition of indolyl-allenes. 
<smiles>[R]C=C([R])C#CC(O)c1ccccc1NC(=O)[O-]</smiles>
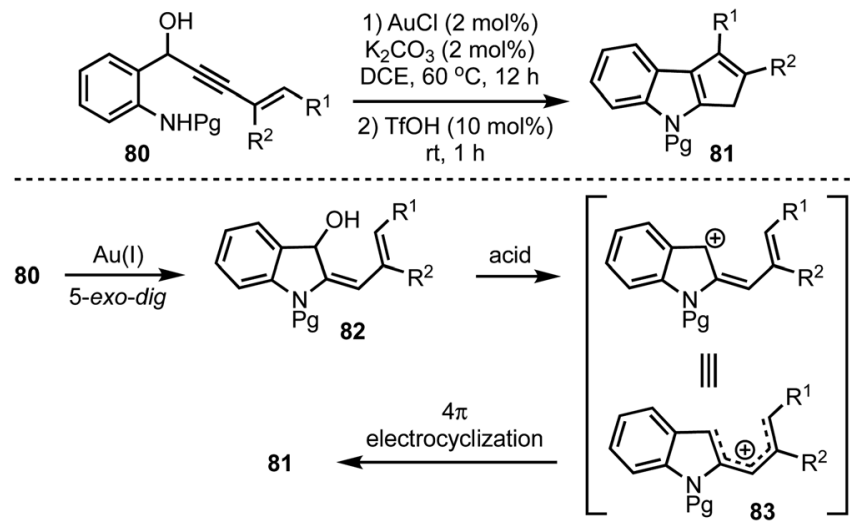

Scheme 21 One-pot synthesis of cyclopentannulated indoles by using sequential gold(I) and Brønsted acid catalysis.
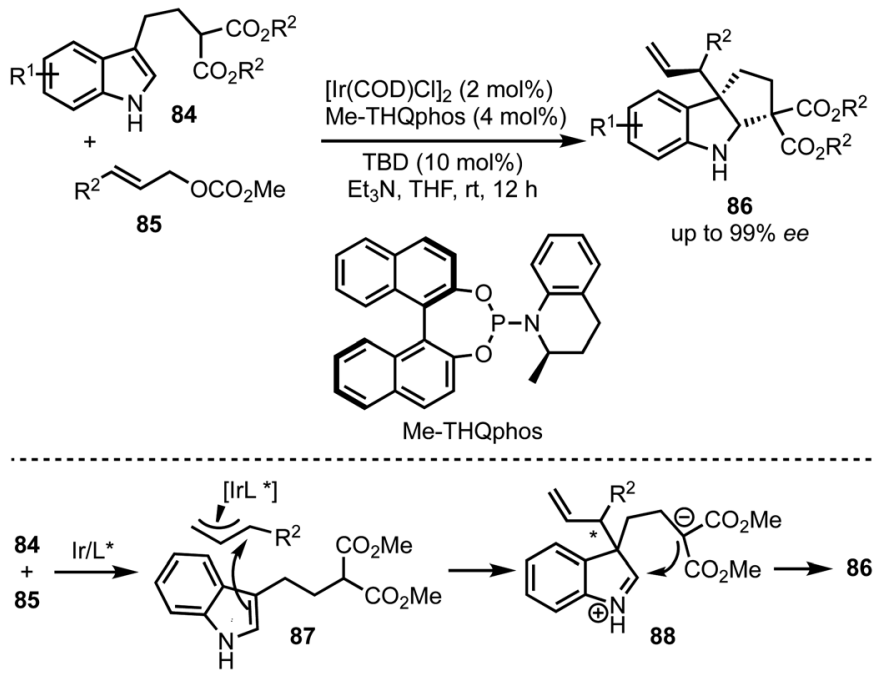

Scheme 22 You's Ir-catalysed intermolecular allylic alkylation reaction of 3-substituted indoles.

carbenoid in $\mathbf{7 6}$ followed by deprotonation and protodeauration provides 71 (path b).

In 2015, Shi and co-workers reported a catalyst-dependent stereodivergent and regioselective construction of indolefused heterocycles $\mathbf{7 8}$ and $\mathbf{7 9}$ from indolyl-allenes 77 (Scheme $20{ }^{44}$ This is an atom-economical method to access indolefused tricyclic systems under mild conditions. Interestingly, reversion in the stereochemistry of an all-carbon quaternary stereocentre in $\mathbf{7 8}$ and $\mathbf{7 9}$ was observed depending on whether gold or platinum complexes were employed during the [3+2]cycloaddition of allenes with indoles. The authors have proposed mechanisms for these transformations based on deuterium labeling studies and control experiments.

Recently, we have disclosed a one-pot indole cyclopentannulation of 1-(2-aminophenyl)pent-4-en-2-ynols $\mathbf{8 0}$ which involves a tandem gold(I)-catalysed intramolecular hydroamination of alkynes followed by Brønsted acid catalysed $4 \pi$-electrocyclisation sequence (Scheme 21). ${ }^{45}$ The proposed mechanism involves an initial $\mathrm{Au}(\mathrm{I})$-catalysed 5-exo-dig cyclisation to form 2-allylidene indolinols 82. Subsequently, under
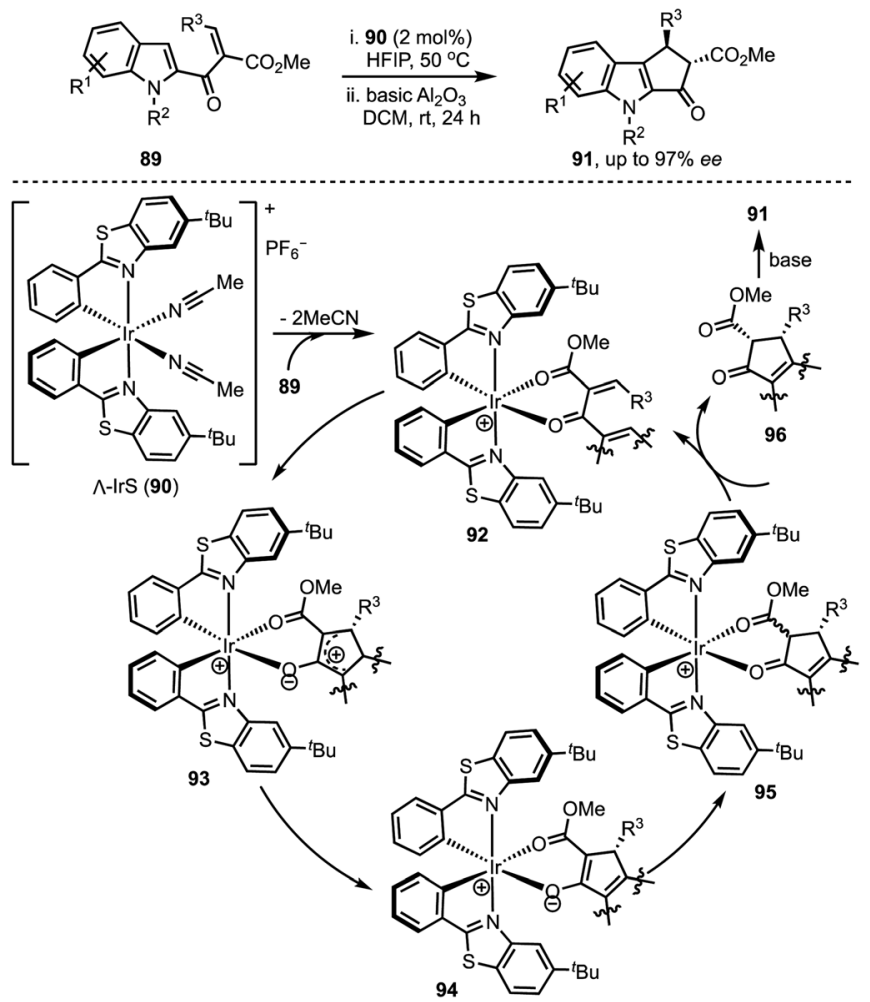

Scheme 23 Meggers' asymmetric Nazarov cyclisation catalysed by chiral-at-metal Ir-complex.

acidic conditions, intermediate 82 generates a pentadienyl cationic system 83, which undergoes Nazarov cyclisation to give 81. This strategy was successfully applied to the synthesis of core carbon structure of the natural product polyveoline, in addition to synthesising several other complex molecular architectures.

\section{Iridium-catalysed approaches}

In 2015, You and co-workers reported an Ir-catalysed asymmetric allylic alkylation of 3-substituted indoles $\mathbf{8 4}$ to access

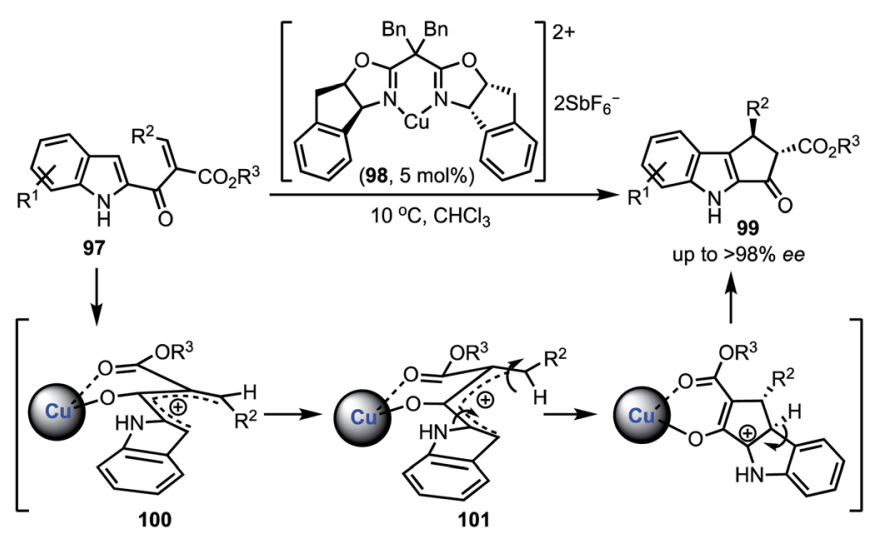

Scheme 24 Rueping's asymmetric Nazarov cyclisation. 

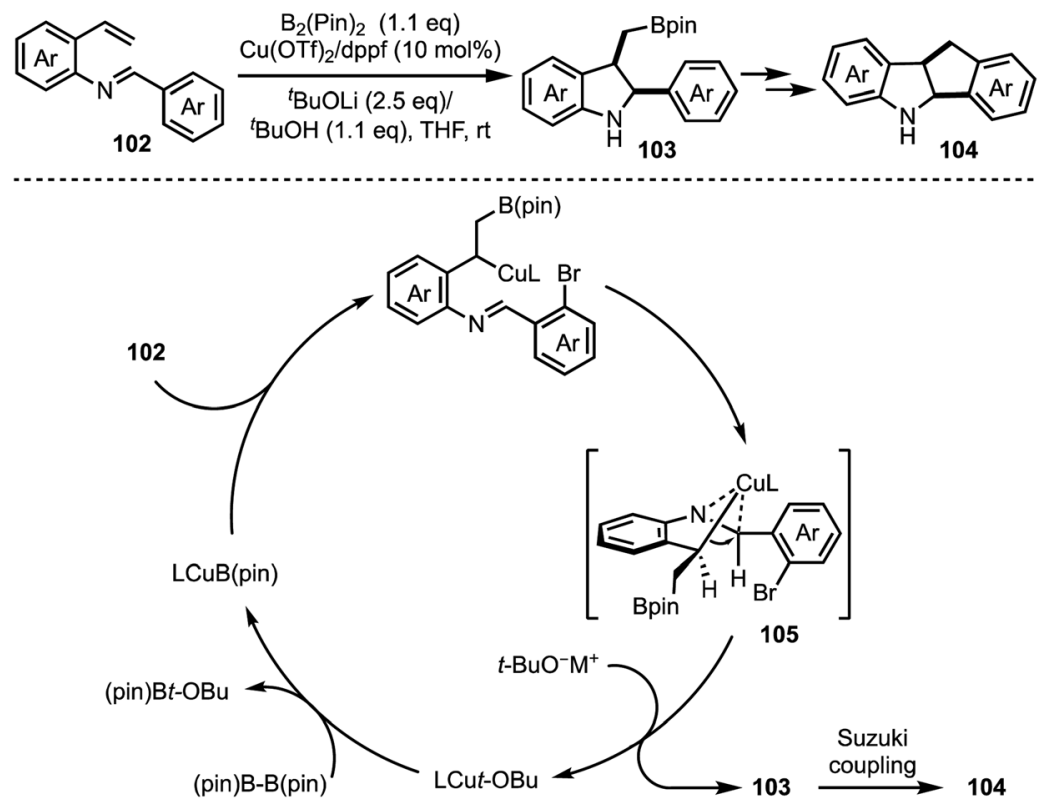

Scheme $25 \mathrm{Cu}(\mathrm{I})$-catalysed borylative cyclisation.

structurally complex cyclopentannulated indolines 86 (Scheme 22). ${ }^{46}$ The transformation is initiated by a Tsuji-Trost reaction between $\pi$-allyl iridium complex and indoles (as in 87 ) leading to the formation of indolines 88. Intramolecular attack of the malonate anion on to the iminium ion (in 88) generates product 86. Versatility of this method was demonstrated via the synthesis of a diverse set of furoindolines, pyrroloindolines and cyclopentaindolines in high regio-, diastereo- and enantioselective manner. Other salient features of this method are: easily accessible starting compounds and inception of three contiguous stereocentres in products.

In 2018, Meggers and co-workers have come up with the synthesis of cyclopenta[ $b]$ indoles 91 via asymmetric Nazarov cyclisation by employing chiral-at-metal Ir-complex 90 (Scheme 23). ${ }^{47}$ The mechanism involves an initial $O, O$-bidentate

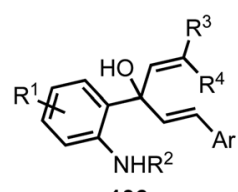

106
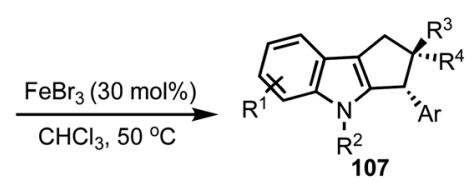

up to $85 \%$ yield
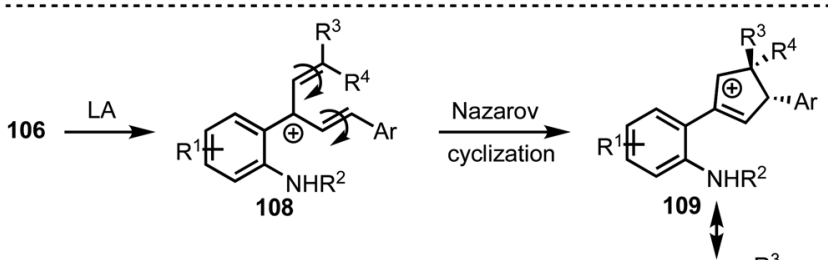

107

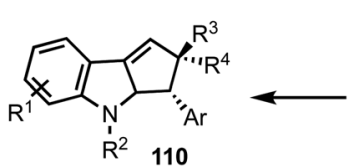

Scheme 26 Kwon's Nazarov cyclisation. coordination of the unsaturated $\beta$-ketoester 89 to the iridium complex (92). A conrotatory electrocylisation leads to the formation of the cationic intermediate 93, and the asymmetric induction is provided by the helical chirality of the $C_{2}$ symmetric iridium complex 90. Subsequent deprotonation and reprotonation of $\mathbf{9 4}$ furnished the catalyst-bound Nazarov product 95. Base-mediated epimerisation of the 2,3-cis-Nazarov product leads to the thermodynamically stable 2,3 -trans product 96. The role of the solvent 1,1,1,3,3,3-hexafluoroisopropanol (HFIP) was found to be crucial in releasing the catalyst bound product $\mathbf{9 5}$, which was attributed to its weak acidity. Thereby, functionalised pentannulated indoles $\mathbf{9 1}$ were obtained in good yields and excellent enantiopurities. Some of the advantages of this work are: low catalyst loading of $\Lambda$-IrS (90, 2 mol\%), avoiding dry solvents and inert atmosphere, etc.

\section{Copper-catalysed approaches}

A Cu-catalysed asymmetric Nazarov cyclisation of indoles was demonstrated by Rueping and co-workers (Scheme 24).48 Through this approach, highly enantioenriched cyclopenta[ $[b]$ indoles 99 were synthesised in the presence of a chiral [Cu ${ }^{\text {II }}($ box $\left.)\right]$ complex 98 in good yields. The proposed mechanism involves a six-membered boat conformation 100, formed between $\mathrm{Cu}(\mathrm{II})$ and $\beta$-keto ester 97 by coordinating with two carbonyl groups. Subsequent isomerisation to $\mathbf{1 0 1}$ and a $4 \pi$-electrocylisation afforded desired products 99 in excellent enantioselectivities. The authors have further explained the origin of the enantioselectivity with the aid of DFT studies.

In 2018, Shen and Xu described a borometalation-imine addition cascade reaction for the synthesis of 2,3-cis-disubstituted indolines 103 by using $\mathrm{Cu}(\mathrm{OTf})_{2}$ as precatalyst (Scheme 25). ${ }^{49}$ The indolines preinstalled with ortho-bromo aryl groups (at indoline C-2 position) were further elaborated to varieties of 


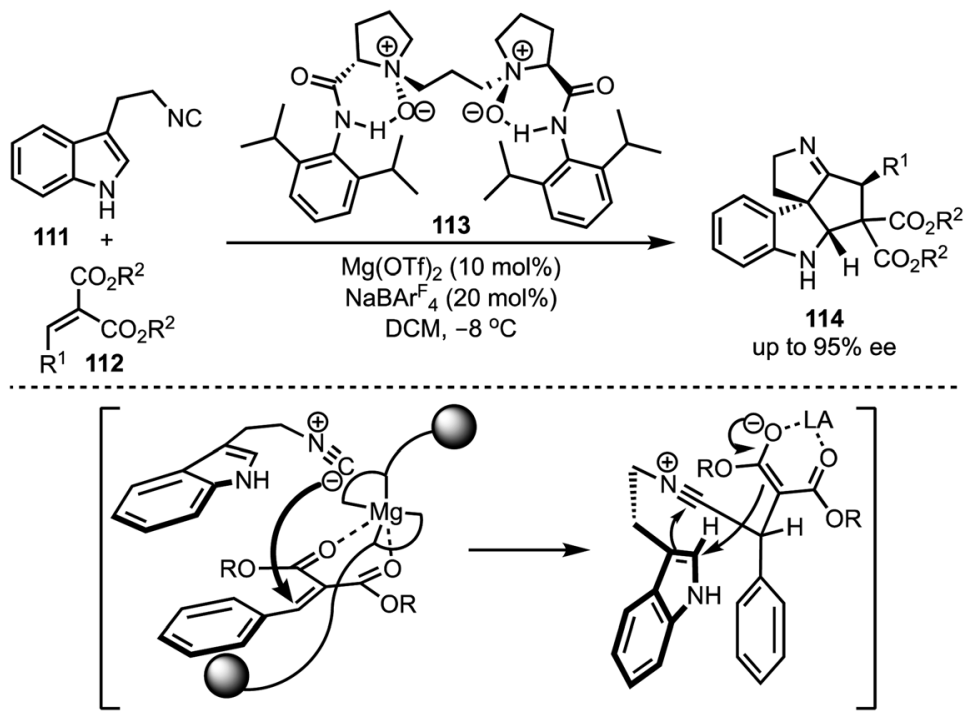

Scheme 27 Liu and Feng's cascade process leading to the synthesis of polycyclic spiroindolines.

cis-tetrahydroindenoindoles 104 in excellent yields through an intramolecular Suzuki coupling. The exclusive diastereoselective formation of cis-2,3-disubstituted indolines is partly attributed to the hypothetical imine-copper coordination complex 105.

\section{Other metal-catalysed approaches}

In 2016, Kwon and co-workers demonstrated an interesting Lewis acid mediated Nazarov cyclisation of 1,4-pentadien-3-ols 106 (Scheme 26)..$^{50}$ An inexpensive and environmental friendly $\mathrm{FeBr}_{3}$ was used as a catalyst for the transformation. A diverse range of cyclopenta[b]indoles $\mathbf{1 0 7}$ were synthesised in a highly regio- and stereoselective manner under mild Lewis acidic conditions. Regarding mechanism, in presence of $\mathrm{FeBr}_{3}, 108$ undergoes Nazarov cyclisation to generate the cationic intermediate 109. A subsequent stereoselective intramolecular nucleophilic amination on to $\mathbf{1 0 9}^{\prime}$ forms $\mathbf{1 1 0}$, which isomerises to cyclopenta $[b]$ indoles $\mathbf{1 0 7}$.
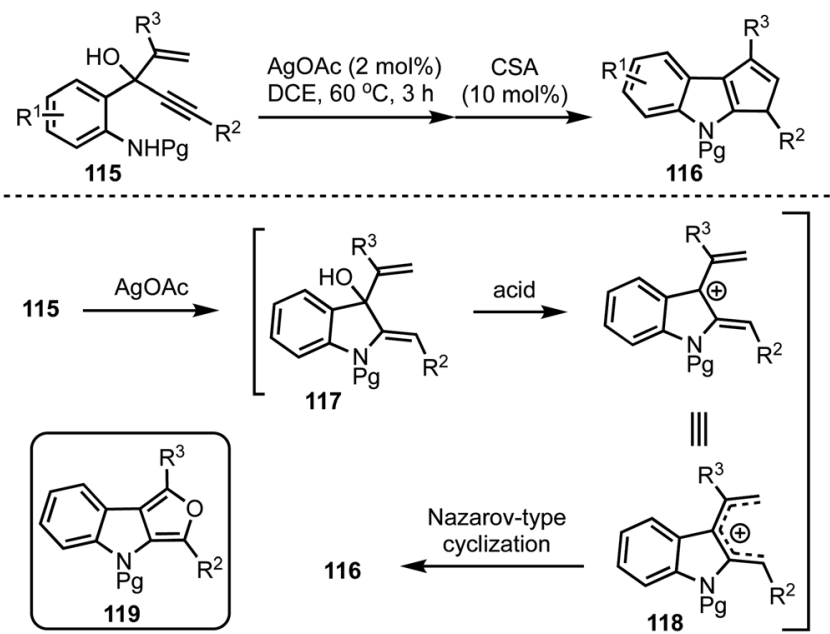

117

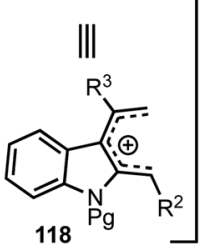

Scheme 28 Ag(I)-catalysed approach for cyclopenta[b]indoles.
In 2015, Liu and Feng have reported an asymmetric dearomatisation of indoles through a cascade Michael/FriedelCrafts-type reaction sequence to construct polycyclic spiroindolines 114 (Scheme 27). ${ }^{51}$ The reaction of 2-isocyanoethyl indoles 111 and alkylidene malonates 112, catalysed by a chiral $N, N^{\prime}$-dioxide $/ \mathrm{Mg}^{\mathrm{II}}$ complex 113, furnished highly functionalised polycyclic indolines 114 possessing up to three stereocentres in good yields, and excellent diastereo- and enantioselectivities. The reaction proceeds via an initial Michael addition of isocyanides to alkylidene malonates which subsequently undergo Friedel-Crafts/Mannich-type reaction to generate complex structures.

Recently, we have developed an efficient synthetic protocol for the synthesis of 1,3-disubstituted cyclopenta[b]indoles 116 via a sequential $\mathrm{Ag}(\mathrm{I}) / \mathrm{Br} ø n$ sted acid catalysis from easily accessible 3-(2-aminophenyl)-4-pentenyn-3-ols 115 (Scheme 28).52 The reaction is initiated by a Ag(I)-catalysed 5-exo-dig cyclisation (117) followed by a Brønsted acid catalysed Nazarov-type cyclisation of pentadienyl cationic system 118 to obtain cyclopenta $[b]$ indoles 116. This divergent strategy also provides access to furo[3,4-b]indoles 119 via a sequential one-pot $\mathrm{Ag}(\mathrm{I}) / \mathrm{Bi}(\mathrm{III}) / \mathrm{Pd}(\mathrm{II})$ catalysis.

In 2017, Liu reported an interesting triflic acid-catalysed cascade reaction involving 2-alkylnylbenzyl alcohols $\mathbf{1 2 0}$ and 1-(2-aminophenyl)prop-2-ynols $\mathbf{1 2 1}$ to access an unusual set of $N, O$-containing pentacyclic cyclopenta[b]indole scaffolds $\mathbf{1 2 2}$ (Scheme 29). ${ }^{53}$ The transformation involves an in situ generation of triflic acid [by combining acetic acid and $\mathrm{Sc}(\mathrm{OTf})_{3}$ ], which promotes cycloisomerisation of alkynol $\mathbf{1 2 0}$ to $\mathbf{1 2 3}$ followed by intermolecular substitution to afford an allene intermediate 124. A sequence of conjugate additions and cyclisation events provide the final product 122. Several control experiments were performed to get insights about the mechanism. The efficiency of this method lies in its ability to construct pentacyclic cyclopentannulated indoles in a single operation, in which two C-C bonds, one $\mathrm{C}-\mathrm{O}$ bond and one $\mathrm{C}-\mathrm{N}$ bond form. 

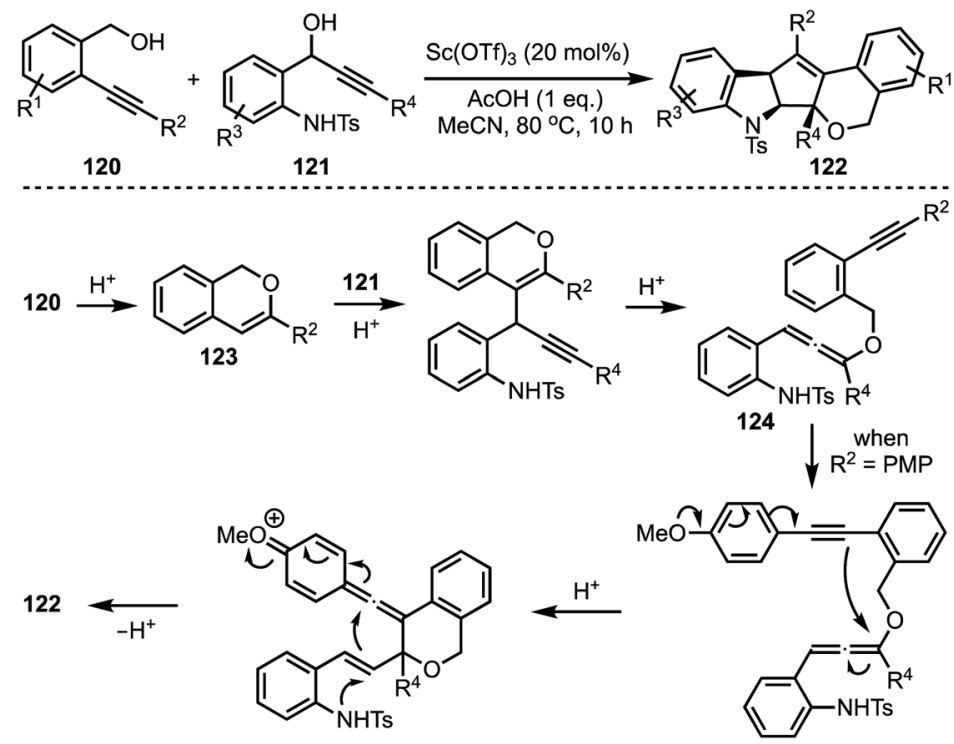

Scheme 29 Liu's cascade approach for the synthesis of pentacyclic cyclopenta[b]indoles.

\section{Conclusion}

Among indole derivatives, cyclopenta $[b]$ indole scaffold is an important structural motif which is widely found in bioactive natural products and pharmaceutically important compounds. Consequently, an array of synthetic protocols have been developed to prepare this heterocyclic core. ${ }^{54}$ Among which, metalcatalysed approaches are popular due to their versatility, broad substrate scope, scalability, wide functional group tolerance, etc. Through this review, a summary of metal-catalysed transformations leading to the synthesis of cyclopenta[b] indoles is presented. In addition to the inspirational contributions from various research groups, our own efforts pertaining to the one-pot synthesis of cyclopentannulated indoles have also been discussed herein. From these deliberations, it is evident that there exist potential opportunities to devise efficient and straightforward enantioselective approaches, especially promoted by non-precious metals. Towards this, the development of one-pot multiple bond-forming multicomponent strategies can offer a potential solution.

Another important aspect that deserves attention at this stage is the development of biomimetic approaches for the synthesis of cyclopenta[$[b]$ indoles. $^{55}$ For example, Nature prepares majority of these heterocycles starting from the amino acid tryptophan. So, the evolution of novel chemical transformations leading to the construction of complex molecular architectures by employing readily available materials is desired. We anticipate that more progress would be realised in this direction.

\section{Conflicts of interest}

The authors declare no conflict of interest.

\section{Acknowledgements}

We sincerely thank IISER Mohali for financial support. T. V. and S. K. B. thank IISER Mohali for research fellowships and B. S. thanks UGC for the research fellowship.

\section{Notes and references}

1 E. Vitaku, D. T. Smith and J. T. Njardarson, J. Med. Chem., 2014, 57, 10257.

2 For general reviews on the synthesis of nitrogen heterocycles, see: $(a)$ G. S. Singh and Z. Y. Desta, Chem. Rev., 2012, 112, 6104; (b) W. A. Nack and G. Chen, Synlett, 2015, 26, 2505; (c) B. Zhang and A. Studer, Chem. Soc. Rev., 2015, 44, 3505.

3 For selected reviews on indole natural products, see:(a) K. Higuchi and T. Kawasaki, Nat. Prod. Rep., 2007, 24, 843; (b) A. J. Kochanowska-Karamyan and M. T. Hamann, Chem. Rev., 2010, 110, 4489; (c) M. Ishikura, T. Abe, T. Choshi and S. Hibino, Nat. Prod. Rep., 2013, 30, 694; (d) I. S. Marcos, R. F. Moro, I. Costales, P. Basabe and D. Díez, Nat. Prod. Rep., 2013, 30, 1509; (e) W. Xu, D. J. Gavia and Y. Tang, Nat. Prod. Rep., 2014, 31, 1474.

4 For recent reviews on the biological significance of indoles, see:(a) S. Olgen, Mini-Rev. Med. Chem., 2013, 13, 1700; (b) N. K. Kaushik, N. Kaushik, P. Attri, N. Kumar, C. H. Kim, A. K. Verma and E. H. Choi, Molecules, 2013, 18, 6620; (c) J. S. Sidhu, R. Singla, E. Y. Mayank and V. Jaitak, Anticancer Agents Med. Chem., 2015, 16, 160.

5 (a) S. Lim, K. Sim, Z. Abdullah, O. Hiraku, M. Hayashi, K. Komiyama and T.-S. Lam, J. Nat. Prod., 2007, 70, 1380; (b) S. B. Jones, B. Simmons, A. Mastracchio and D. W. C. MacMillan, Nature, 2011, 475, 183; (c) D. H. Dethe, R. D. Erande and A. Ranjan, J. Org. Chem., 2013, 78, 10106; (d) R. Neelamegam, T. Hellenbrand, 
F. A. Schroeder, C. Wang and J. M. Hooker, J. Med. Chem., 2014, 57, 1488.

6 (a) K. Stratmann, R. E. Moore, R. Bonjouklian, J. B. Deeter, G. M. L. Patterson, S. Shaffer, C. D. Smith and T. A. Smitka, J. Am. Chem. Soc., 1994, 116, 9935; (b) J. M. Richter, Y. Ishihara, T. Masuda, B. W. Whitefield, T. Llamas, A. Pohjakallio and P. S. Baran, J. Am. Chem. Soc., 2008, 130, 17938.

7 J. Nakazawa, J. Yajima, T. Usui, M. Ueki, A. Takatsuki, M. Imoto, Y. Y. Toyoshima and H. Osada, Chem. Biol., 2005, 10, 131.

8 (a) Y. C. Kong, K. H. Ng, K. H. Wat, A. Wong, I. F. Saxena, K. F. Cheng, P. P. H. But and H. T. Chang, Planta Med., 1985, 304; (b) C. Kong, K.-F. Cheng, R. C. Cambie and P. G. Waterman, J. Chem. Soc., Chem. Commun., 1985, 47; (c) H. Chen, J. Bai, Z.-F. Fang, S.-S. Yu, S.-G. Ma, S. Xu, Y. Li, J. Qu, J.-H. Ren and L. Li, J. Nat. Prod., 2011, 74, 2438.

9 (a) J. A. Jordan, G. W. Gribble and J. C. Badenock, Tetrahedron Lett., 2011, 52, 6772; (b) D. Scarpi, C. Faggi and E. G. Occhiato, J. Nat. Prod., 2017, 80, 2384.

10 S. C. Munday-Finch, A. L. Wilkins and C. O. Miles, J. Agric. Food Chem., 1998, 46, 590.

11 E. Lai, I. De Lepeleire, T. M. Crumley, F. Liu, L. A. Wenning, N. Michiels, E. Vets, G. O'Neill, J. A. Wagner and K. Gottesdiener, Clin. Pharmacol. Ther., 2007, 81, 849.

12 (a) A. Cave, H. Guinaudeau, H. M. Leboeuf, A. Ramahatra and J. Razafindrazaka, Planta Med., 1978, 33, 243; (b) B. Nyasse, I. Ngantchou, J.-J. Nono and B. Schneider, Nat. Prod. Res., 2006, 20, 391; (c) I. Ngantchou, B. Nyasse, C. Denier, C. Blonski, V. Hannaert and B. Schneider, Bioorg. Med. Chem. Lett., 2010, 20, 3495; (d) S. F. Kouam, A. W. Ngouonpe, M. Lamshoft, F. M. Talontsi, J. O. Bauer, C. Strohmann, B. T. Ngadjui, H. Laatsch and M. Spiteller, Phytochemistry, 2014, 105, 52.

13 (a) W. Tan, X. Li, Y. X. Gong, M. D. Ge and F. Shi, Chem. Commun., 2014, 50, 15901; (b) H. Li, R. P. Hughes and J. J. Wu, J. Am. Chem. Soc., 2014, 136, 6288.

14 S. Gérard, A. Renzetti, B. Lefevre, A. Fontana, P. Maria and J. Sapi, Tetrahedron, 2010, 66, 3065.

15 W. Zi, H. Wu and F. D. Toste, J. Am. Chem. Soc., 2015, 137, 3225.

16 (a) G. M. Shelke, V. K. Rao, R. Tiwari, B. S. Chhikara, K. Parang and A. Kumar, RSC Adv., 2013, 3, 22346; (b) M. Rueping and B. J. Nachtsheim, Top. Curr. Chem., 2011, 311, 115.

17 (a) J. A. Malona, J. M. Colbourne and A. J. Frontier, Org. Lett., 2006, 8, 5661; (b) J. Davies and D. Leonori, Chem. Commun., 2014, 50, 15171; (c) N. S. Sheikh, Org. Biomol. Chem., 2015, 13, 10774.

18 (a) A. Ekebergh, I. Karlsson, R. Mete, Y. Pan, A. Börje and J. Mårtensson, Org. Lett., 2011, 13, 4458; (b) A. Ekebergh, A. Börje and J. Mårtensson, Org. Lett., 2012, 14, 6274.

19 (a) B. A. Haag, Z. G. Zhang, J. S. Li and P. Knochel, Angew. Chem., Int. Ed., 2010, 49, 9513; (b) A. G. K. Reddy and G. Satyanarayana, Synthesis, 2015, 47, 1269.

20 A. Ganesan and C. H. Heathcock, Tetrahedron Lett., 1993, 34, 439.
21 (a) O. Miyata, N. Takeda, Y. Kimura, Y. Takemoto, N. Tohnai, M. Miyata and T. Naito, Tetrahedron, 2006, 62, 3629; (b) O. Miyata and T. Naito, Chem. Commun., 1999, 2429.

22 A. Palmieri and M. Petrini, J. Org. Chem., 2007, 72, 1863.

23 F. Shi, H.-H. Zhang, X.-X. Sun, J. Liang, T. Fan and S. -J. Tu, Chem.-Eur. J., 2015, 21, 3465.

24 E. P. Balskus, R. J. Case and C. T. Walsh, FEMS Microbiol. Ecol., 2011, 77, 322.

25 M. Petrovic and E. G. Occhiato, Chem.-Asian J., 2016, 11, 642. 26 J. Chen, X. Han and X. Lu, J. Org. Chem., 2017, 82, 1977.

27 S. Duan, B. Cheng, X. Duan, B. Bao, Y. Li and H. Zhai, Org. Lett., 2018, 20, 1417.

28 S. Kotha and R. Gunta, J. Org. Chem., 2017, 82, 8527.

29 A. Ekebergh, C. Lingblom, P. Sandin, C. Wennerås and J. Mårtensson, Org. Biomol. Chem., 2015, 13, 3382.

30 S. S. K. Boominathan and J.-J. Wang, Chem.-Eur. J., 2015, 21, 17044.

31 M. Laugeois, J. Ling, C. Férard, V. Michelet, V. Ratovelomanana-Vidal and M. R. Vitale, Org. Lett., 2017, 19, 2266.

32 M. Sun, Z.-Q. Zhu, L. Gu, X. Wan, G.-J. Mei and F. Shi, J. Org. Chem., 2018, 83, 2341.

33 (a) Y. S. Gee, D. J. Rivinoja, S. M. Wales, M. G. Gardiner, J. H. Ryan and C. J. T. Hyland, J. Org. Chem., 2017, 82, 13517; (b) D. J. Rivinoja, Y. S. Gee, M. G. Gardiner, J. H. Ryan and C. J. T. Hyland, ACS Catal., 2017, 7, 1053.

34 J.-Q. Zhang, F. Tong, B.-B. Sun, W.-T. Fan, J.-B. Chen, D. Hu and X.-W. Wang, J. Org. Chem., 2018, 83, 2882.

35 S. K. Bankar, B. Singh, P. Tung and S. S. V. Ramasastry, Angew. Chem., Int. Ed., 2018, 57, 1678.

36 K. L. Vickerman and L. M. Stanley, Org. Lett., 2017, 19, 5054. 37 C. Jing, Q.-Q. Cheng, Y. Deng, H. Arman and M. P. Doyle, Org. Lett., 2016, 18, 4550.

38 L. Jiang, W. Jin and W. Hu, ACS Catal., 2016, 6, 6146.

39 C.-Y. Wu, Y.-N. Yu and M.-H. Xu, Org. Lett., 2017, 19, 384.

40 K. Chen, Z.-Z. Zhu, J.-X. Liu, X.-Y. Tang, Y. Weib and M. Shi, Chem. Commun., 2018, 54, 2870.

41 S. Dhiman and S. S. V. Ramasastry, Chem. Commun., 2015, 51, 557.

42 D. Scarpi, M. Petrović, B. Fiser, E. Gómez-Bengoa and E. G. Occhiato, Org. Lett., 2016, 18, 3922.

43 J. Liu, M. Chen, L. Zhang and Y. Liu, Chem.-Eur. J., 2015, 21, 1009.

44 L.-Y. Mei, Y. Wei, X.-Y. Tang and M. Shi, J. Am. Chem. Soc., 2015, 137, 8131.

45 S. Dhiman and S. S. V. Ramasastry, Org. Lett., 2015, 17, 5116. 46 X. Zhang, W.-B. Liu, H.-F. Tua and S.-L. You, Chem. Sci., 2015, 6, 4525.

47 T. Mietke, T. Cruchter, V. A. Larionov, T. Faber, K. Harmsa and E. Meggers, Adv. Synth. Catal., 2018, 360, DOI: 10.1002/adsc.201701546.

48 S. Raja, M. Nakajima and M. Rueping, Angew. Chem. Int. Ed, 2015, 54, 2762.

49 H.-M. Wang, H. Zhou, Q.-S. Xu, T.-S. Liu, C.-L. Zhuang, M.-H. Shen and H.-D. Xu, Org. Lett., 2018, 20, 1777.

50 Z. Wang, X. Xu, Z. Gu, W. Feng, H. Qian, Z. Li, X. Suna and O. Kwon, Chem. Commun., 2016, 52, 2811. 
51 X. Zhao, X. Liu, H. Mei, J. Guo, L. Lin and X. Feng, Angew. Chem. Int. Ed, 2015, 54, 4032.

52 Manisha, S. Dhiman, J. Mathew and S. S. V. Ramasastry, Org. Biomol. Chem., 2016, 14, 5563.

53 X.-F. Mao, X.-P. Zhu, D.-Y. Li, L.-L. Jiang and P.-N. Liu, Chem. Commun., 2017, 53, 8608.
54 While this manuscript was under review, the following goldcatalysed approach for the synthesis of cyclopenta[b]indoles was published: M. Lin, L. Zhu, J. Xia, Y. Yu, J. Chen, Z. Mao and X. Huang, Adv. Synth. Catal., 2018, DOI: 10.1002/ adsc. 201800001.

55 D. H. Dethe and B. V. Kumar, Org. Chem. Front., 2015, 2, 548. 